BMJ Open

Diabetes

Research

\& Care

\title{
Intensity of statin therapy and new hospitalizations for heart failure in patients with type 2 diabetes
}

\author{
Ichiro Kishimoto, ${ }^{1}$ Hisashi Makino, ${ }^{1}$ Yoko Ohata, ${ }^{1}$ Tamiko Tamanaha, ${ }^{1}$ \\ Mayu Tochiya, ${ }^{1}$ Toshihisa Anzai, ${ }^{2}$ Kengo Kusano, ${ }^{2}$ Teruo Noguchi, ${ }^{2}$ \\ Satoshi Yasuda, ${ }^{2}$ Hisao Ogawa ${ }^{2}$
}

To cite: Kishimoto I, Makino $\mathrm{H}$, Ohata $\mathrm{Y}$, et al. Intensity of statin therapy and new hospitalizations for heart failure in patients with type 2 diabetes. BMJ Open Diabetes Research and Care 2015;3 e000137. doi:10.1136/ bmjdrc-2015-000137

- Additional material is available. To view please visit the journal (http://dx.doi.org/ 10.1136/bmjdrc-2015000137)

Received 22 July 2015 Revised 2 October 2015 Accepted 9 October 2015

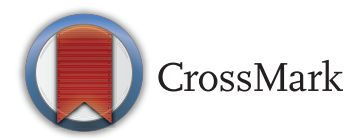

\footnotetext{
${ }^{1}$ Department of Endocrinology and Metabolism, National Cerebral and Cardiovascular Center, Osaka, Japan

2Department of Cardiovascular Medicine, National Cerebral and Cardiovascular Center, Osaka, Japan
}

Correspondence to Dr Ichiro Kishimoto; kishimot@hsp.ncvc.go.jp

\section{ABSTRACT}

Objective: To examine a relationship between statin intensity and heart failure (HF) incidence in diabetes. Research design and methods: We performed a retrospective cohort study of patients with type 2 diabetes $(n=600$; age, 66.3 years; men, 68\%). Patients were categorized into three groups by baseline statin treatments-moderate-intensity, low-intensity, or no statin-and the independent association between the statin category and HF hospitalization during follow-up was examined.

Results: Over the course of the median 6-year followup, $17.7 \%$ of the patients were hospitalized for HF. Cox regression analysis revealed a significant association between the baseline statin category and HF incidence $(p=0.002)$, independently of age, sex, hypertension, Btype natriuretic peptide, glycated hemoglobin, estimated glomerular filtration rate, and low-density lipoprotein (LDL) cholesterol levels. The moderateintensity statin group had a significantly lower risk for HF than the low-intensity statin group with an adjusted $\mathrm{HR}$ of 0.31 (95\% Cl 0.13 to $0.65, \mathrm{p}=0.0014)$. Interestingly, among patients with prevalent coronary artery diseases (CAD) and with baseline LDL controlled to less than $100 \mathrm{mg} / \mathrm{dL}$, the frequency of HF was still significantly lower in the moderate-intensity group than in the low-intensity group or the no statin group. The effect of baseline statin category on HF was independent of incident CAD events during follow-up. Conclusions: In type 2 diabetes, moderate-intensity statins, in comparison to low-intensity or no statin, were associated with lower HF incidence independently of LDL levels or of CAD events.

\section{INTRODUCTION}

Clinical trials in patients with high risk for coronary artery diseases (CAD) have demonstrated that high doses of statins lead to a significant reduction in mortality and morbidity. ${ }^{1-3}$ Therefore, in patients with high cardiovascular risk or with prevalent CAD, high-dose statins are recommended in the clinical guidelines. ${ }^{45}$

Trials with statins have also shown significant prevention of CAD events or mortality

\section{Key messages}

- Patients with type 2 diabetes taking moderate-intensity statins had a significantly lower heart failure risk than those taking lowintensity or no statins.

- The association between the statin category and heart failure development persisted after taking into account possible confounding factors including levels of low-density lipoprotein (LDL) cholesterol, B-type natriuretic peptide (BNP), or echocardiographic parameters at baseline, or coronary events during follow-up.

- Even in those with baseline LDL levels controlled to less than $100 \mathrm{mg} / \mathrm{dL}$, the moderate-intensity statin group had significantly lower heart failure incidence than the low-intensity or no statin group.

- The effect of the statin category is apparent, especially in diabetes with prevalent coronary artery diseases or with $\mathrm{BNP}<100 \mathrm{pg} / \mathrm{mL}$.

in patients with diabetes. ${ }^{6}$ Meta-analyses have revealed the overall benefits of statin therapy for CAD prevention, especially in those with moderate or high cardiovascular risk. ${ }^{78}$

In addition to the lipid-lowering capabilities, statins seem to have pleiotropic effects that could affect cardiac remodeling, inflammation, and oxidative stress. ${ }^{9} 10$ However, while statins have become a standard in the prevention and treatment of CAD, it is not fully understood whether and which statins are effective in the prevention of heart failure (HF). In the present study, we therefore examined the difference in $\mathrm{HF}$ incidence among patients with diabetes taking moderate-intensity, low-intensity, and no statins at baseline in our retrospective cohort.

\section{RESEARCH DESIGN AND METHODS Participants}

The study population selection is detailed elsewhere. ${ }^{11}$ In brief, of 1345 patients 
referred to our facility between March 2000 and November 2007, 826 who were diagnosed with type 2 diabetes were selected for the study. Sixty-two patients were excluded because they had diagnoses of acute HF or exacerbation of chronic $\mathrm{HF}$ at the time of referral, or they were symptomatic for HF (classes 2-4 of the New York Heart Association (NYHA) functional classification). Therefore, all eligible patients with type 2 diabetes were asymptomatic for HF (NYHA class 1) at baseline. In this study, we further excluded patients diagnosed with primary hyperlipidemia including familial hypercholesterolemia at baseline. Among the rest, 600 patients with type 2 diabetes who underwent screening echocardiography for baseline cardiac function were selected. Opportunities to opt out of participation were provided to all patients.

\section{Clinical variables and diagnosis of diseases}

Anthropometric, clinical, and laboratory data including age, sex, body mass index (BMI), blood pressure, plasma B-type natriuretic peptide (BNP) levels, estimated glomerular filtration rate (eGFR), and low-density lipoprotein (LDL) levels using the Friedewald formula were obtained at baseline. Diabetes was diagnosed at baseline on the basis of plasma glucose levels, physician's diagnosis, or history of medical treatment for diabetes. Prevalent and incident HF were diagnosed clinically by expert cardiologists, who are independent of the authors of the current paper. Prevalent HF was identified when the patient had a previous diagnosis of $\mathrm{HF}$ in their medical records. Incident HF was defined either as death from HF (3.8\% of total events) or as the first HF hospitalization during follow-up shown at the top of the hospital coding list. Prevalent CAD includes myocardial infarction (MI) with elevated cardiac enzymes, angina pectoris with coronary stenosis, documented myocardial ischemia, or a prior coronary reperfusion procedure at baseline. The CAD incident was defined as the first hospitalization during follow-up due to acute coronary syndrome (ACS), including MI with elevated cardiac enzymes, unstable angina with documented coronary arterial lesions, coronary reperfusion procedure, or coronary arterial bypass operation.

\section{Statin intensities}

Although atorvastatin (40-80 mg) and rosuvastatin (20$40 \mathrm{mg}$ ) were defined as the high-intensity statin regimens, ${ }^{4}$ usual doses of atorvastatin and rosuvastatin in Japan were equal to or less than $20 \mathrm{mg}$ and $10 \mathrm{mg}$, respectively. In this study, the patients taking atorvastatin $(5-20 \mathrm{mg})$, rosuvastatin $(2.5-5 \mathrm{mg})$, or pitavastatin (2$4 \mathrm{mg}$ ) were categorized to the moderate-intensity statin group, while the low-intensity statin group includes the patients taking pitavastatin (1 mg), pravastatin (5$20 \mathrm{mg}$ ), simvastatin (2.5-10 mg), or fluvastatin (20$30 \mathrm{mg}$ ), according to the 2013 American College of Cardiology (ACG)/American Heart Association (AHA) guideline. ${ }^{4}$ The proportion of patients taking statins in this study is shown in online supplementary table S1.

\section{Statistical analyses}

Baseline characteristics according to the statin category (moderate-intensity, low-intensity, and no statin therapy) were compared using one-way analysis of variance (ANOVA). The follow-up was terminated at the time of either the HF event or at the end of the observation (10 years at maximum). For the person without hospitalization for HF during the follow-up, the HF-free survival time was considered to be as long as the duration of the observation. To calculate the proportion of individuals free of incident HF during follow-up, the Kaplan-Meier method was used. The statistical difference between the statin categories was examined using the log-rank test. In the moderate-intensity and low-intensity statin categories, the relative risks of $\mathrm{HF}$ were calculated using the Cox proportional hazard models with the no statin therapy category or low-intensity statin category as a reference, adjusting for age, sex, hypertension, $\ln [\mathrm{BNP}(\mathrm{pg} / \mathrm{mL})]$, glycated hemoglobin (HbA1c), eGFR, and LDL cholesterol as covariates. Since BNP reflects asymptomatic cardiac dysfunction, ${ }^{12}$ we included plasma BNP levels in the adjustment factors unless otherwise indicated.

In the subgroup analysis, the study population was divided by the presence/absence of prevalent $\mathrm{CAD}$, by LDL cholesterol levels (less than/equal to or more than $100 \mathrm{mg} / \mathrm{dL}$ ), or by plasma BNP levels (less than or more than/equal to $100 \mathrm{pg} / \mathrm{mL}$ ), and HRs for the statin category on HF hospitalization were calculated in each subgroup. In addition, to determine the effect of CAD events, a potential confounding factor for HF events, the association between the baseline statin category and the CAD events during follow-up was also examined. The additional analysis was also performed by censoring patients who developed CAD prior to $\mathrm{HF}$ at the time of the CAD event. Furthermore, to exclude the potential sampling bias, the sensitivity analysis was performed only in patients with whom the observation was started during the latter half of the entry period (ie, from November 2005 to November 2007).

All analyses were conducted using JMP V.12.0.1 (SAS Institute, Cary, North Carolina, USA) statistical software. All $\mathrm{p}$ values were two tailed, and values less than 0.05 were considered statistically significant. All CI were calculated at the $95 \%$ level. Data are expressed as means \pm SD unless otherwise indicated.

\section{RESULTS}

\section{Baseline characteristics}

At the baseline, the proportions of patients taking moderate-intensity, low-intensity, and no statins were $23 \%, 31 \%$, and $46 \%$, respectively. As shown in table 1 , the statin categories were significantly associated with age, BMI, and HbAlc levels. In the increasing statin category, prevalence of hypertension, $\mathrm{CAD}$, asynergy of the 
Table 1 Baseline characteristics of continuous (above) and categorical (below) variables in all patients with type 2 diabetes or according to the statin category

\begin{tabular}{|c|c|c|c|c|c|c|c|c|c|c|c|c|c|}
\hline \multirow[b]{3}{*}{ Variables } & \multicolumn{3}{|l|}{ ALL } & \multicolumn{9}{|c|}{ Statin category } & \multirow[b]{3}{*}{ p Value } \\
\hline & \multirow[b]{2}{*}{ Average } & \multirow[b]{2}{*}{ SD } & \multirow[b]{2}{*}{ Number } & \multicolumn{3}{|l|}{ None } & \multicolumn{3}{|c|}{ Low intensity } & \multicolumn{3}{|c|}{ Moderate intensity } & \\
\hline & & & & Average & SD & Number & Average & SD & Number & Average & SD & Number & \\
\hline Age (years) & 66.3 & 9.6 & 600 & 66.5 & 10.2 & 276 & 67.7 & 9.5 & 186 & 64.1 & 8.1 & 138 & $0.004^{a}$ \\
\hline BMI $\left(\mathrm{kg} / \mathrm{m}^{2}\right)$ & 25.2 & 4.2 & 600 & 24.7 & 4.1 & 276 & 25.9 & 4.6 & 186 & 25.3 & 3.9 & 138 & $0.01^{a}$ \\
\hline Sys BP (mm Hg) & 136.4 & 18.3 & 598 & 136.1 & 18.0 & 275 & 135.9 & 17.4 & 185 & 137.9 & 20.1 & 138 & 0.57 \\
\hline Dia BP (mm Hg) & 73.4 & 10.9 & 596 & 72.8 & 10.5 & 275 & 73.1 & 11.1 & 184 & 74.9 & 11.5 & 137 & 0.18 \\
\hline IVS (mm) & 10.2 & 2.0 & 582 & 10.3 & 2.1 & 268 & 10.1 & 1.9 & 179 & 10.0 & 2.2 & 135 & 0.22 \\
\hline LVPW (mm) & 10.2 & 1.7 & 579 & 10.1 & 1.7 & 266 & 10.2 & 1.5 & 178 & 10.2 & 1.7 & 135 & 0.66 \\
\hline LVDd (mm) & 48.5 & 7.7 & 600 & 48.4 & 7.5 & 276 & 48.1 & 7.3 & 186 & 49.3 & 8.8 & 138 & 0.38 \\
\hline LVDs (mm) & 32.6 & 9.0 & 594 & 32.3 & 8.7 & 272 & 32.5 & 8.7 & 184 & 33.3 & 9.9 & 138 & 0.53 \\
\hline EF (\%) & 55.9 & 13.3 & 594 & 56.6 & 13.1 & 272 & 55.1 & 14.0 & 184 & 55.7 & 12.7 & 138 & 0.51 \\
\hline$E / A$ & 1.1 & 4.3 & 415 & 0.9 & 0.7 & 174 & 0.9 & 0.5 & 135 & 1.7 & 8.4 & 106 & 0.29 \\
\hline $\mathrm{DcT}(\mathrm{ms})$ & 231.8 & 60.9 & 439 & 232.6 & 63.3 & 187 & 231.7 & 62.3 & 144 & 230.6 & 54.8 & 108 & 0.96 \\
\hline In [BNP (pg/mL)] & 3.69 & 1.26 & 600 & 3.68 & 1.30 & 276 & 3.73 & 1.25 & 186 & 3.65 & 1.22 & 138 & 0.83 \\
\hline T-chol (mg/dL) & 185.3 & 41.9 & 599 & 185.6 & 43.4 & 276 & 185.3 & 34.0 & 185 & 184.8 & 48.2 & 138 & 0.99 \\
\hline TG (mg/dL) & 152.5 & 105.4 & 550 & 151.9 & 113.6 & 251 & 142.9 & 71.8 & 171 & 166.4 & 124.0 & 128 & 0.16 \\
\hline HDL-chol (mg/dL) & 42.4 & 12.6 & 596 & 41.6 & 12.9 & 274 & 43.0 & 11.7 & 184 & 43.0 & 13.0 & 138 & 0.43 \\
\hline LDL-chol (mg/dL) & 112.1 & 31.7 & 534 & 113.7 & 27.8 & 242 & 113.6 & 29.8 & 169 & 106.7 & 40.0 & 123 & 0.10 \\
\hline FPG $(\mathrm{mg} / \mathrm{dL})$ & 151.3 & 52.9 & 550 & 146.8 & 47.6 & 251 & 154.9 & 59.2 & 172 & 155.3 & 53.6 & 127 & 0.19 \\
\hline $\mathrm{HbA} 1 \mathrm{c}(\%)$ & 9.1 & 1.8 & 600 & 9.0 & 1.8 & 276 & 9.2 & 1.7 & 186 & 9.4 & 1.7 & 138 & $0.04^{a}$ \\
\hline $\mathrm{HbA} 1 \mathrm{c}(\mathrm{mmol} / \mathrm{mol})$ & 76 & 19.7 & & 75 & 1.8 & & 77 & 18.6 & & 79 & 18.6 & & \\
\hline eGFR $\left(\mathrm{mL} / \mathrm{min} / 1.73 \mathrm{~m}^{2}\right)$ & 64.8 & 25.0 & 600 & 67.2 & 26.6 & 276 & 63.5 & 22.7 & 186 & 61.8 & 24.6 & 138 & 0.08 \\
\hline Variables & Number & Per cent & & Number & Per cent & & Number & Per ce & & Number & Per cent & & \\
\hline Gender (male) & 410 & 68 & & 193 & 70 & & 116 & 62 & & 101 & 73 & & 0.09 \\
\hline Smoking & 117 & 20 & & 51 & 18 & & 32 & 17 & & 34 & 25 & & 0.10 \\
\hline Alcohol & 274 & 46 & & 136 & 49 & & 78 & 42 & & 60 & 43 & & 0.10 \\
\hline Hypertension & 492 & 82 & & 213 & 77 & & 161 & 87 & & 118 & 86 & & $0.02^{\mathrm{a}}$ \\
\hline LV asynergy & 174 & 29 & & 49 & 18 & & 63 & 34 & & 62 & 46 & & $0.0001^{a}$ \\
\hline $\mathrm{CHF}$ & 53 & 9 & & 25 & 9 & & 17 & 9 & & 11 & 8 & & 0.91 \\
\hline CAD & 318 & 53 & & 114 & 41 & & 110 & 59 & & 94 & 68 & & $0.0001^{a}$ \\
\hline Valvular diseases & 36 & 10 & & 25 & 16.0 & & 5 & 4.6 & & 6 & 6.5 & & $0.0036^{a}$ \\
\hline Atrial fibrillation & 62 & 10 & & 36 & 13.0 & & 18 & 9.7 & & 8 & 5.8 & & 0.069 \\
\hline PAD & 87 & 15 & & 25 & 9.1 & & 37 & 19.9 & & 25 & 18.1 & & $0.002^{a}$ \\
\hline
\end{tabular}

${ }^{\mathrm{a}} \mathrm{p}<0.05$.

BMI, body mass index; BNP, B-type natriuretic peptide; CAD, coronary artery disease; CHF, congestive heart failure; DcT, deceleration time; Dd, diastolic dimension; Dia BP, diastolic blood pressure; Ds, systolic dimension; E/A, the ratio of peak early LV filling velocity to late diastolic atrial filling velocity; EF, ejection fraction; eGFR, estimated glomerular filtration rate; FPG, fasting plasma glucose; HbA1c, glycated hemoglobin; HDL, high-density lipoprotein; IVS, interventricular septum; LDL, low-density lipoprotein; LV, left ventricular; PAD, peripheral artery disease; PW, posterior wall; Sys BP, systolic blood pressure; T-chol, total cholesterol; TG, triglyceride. 
left ventricular wall and peripheral artery diseases are higher. There was no statistical difference among statin groups with respect to sex, blood pressure, ln [BNP $(\mathrm{pg} / \mathrm{mL})]$, echocardiographic parameters, or prevalence of HF. The mean baseline LDL levels in the moderate-intensity, low-intensity, and no statin groups were $106.7 \pm 40 \mathrm{mg} / \mathrm{dL}, \quad 113.6 \pm 29.6 \mathrm{mg} / \mathrm{dL}$, and 113.7 $\pm 27.8 \mathrm{mg} / \mathrm{dL}$, respectively $(\mathrm{p}=0.1)$.

\section{Baseline LDL levels in each statin category stratified by prevalent CAD}

In the patients without prevalent $\mathrm{CAD}$ at the baseline, the proportions of each statin category were $15.6 \%$ for the moderate-intensity statin group, $27.0 \%$ for the lowintensity statin group, and $57.5 \%$ for the no statin group. The mean baseline LDL levels in the moderate-intensity, low-intensity, and no statin groups were $119 \pm 48 \mathrm{mg} / \mathrm{dL}, 120 \pm 33 \mathrm{mg} / \mathrm{dL}$, and $116 \pm 31 \mathrm{mg} /$ $\mathrm{dL}$, respectively, and there was no significant difference among the statin categories $(\mathrm{p}=0.70)$ (see online supplementary table S2).

On the other hand, in the patients with prevalent $\mathrm{CAD}$, the proportions of each statin category were $29.6 \%$ for the moderate-intensity statin group, $34.6 \%$ for the low-intensity statin group, and $35.9 \%$ for the no statin group. The mean baseline LDL levels in the moderate-intensity, low-intensity, and no statin groups were $101 \pm 35 \mathrm{mg} / \mathrm{dL}, 109 \pm 27 \mathrm{mg} / \mathrm{dL}$, and $111 \pm 22 \mathrm{mg} /$ $\mathrm{dL}$, respectively $(\mathrm{p}=0.05)$ (see online supplementary table S2).

\section{Hospitalization for HF}

Over the course of the median 6-year follow-up, $17.7 \%$ of the patients were diagnosed as incident HF. The cumulative rates of new hospitalization for HF according to the statin category are shown in figure 1A. The Kaplan-Meier analysis showed separation between the moderate-intensity and no statin groups. In contrast, no apparent difference was observed between the lowintensity and no statin groups. The difference among the cumulative incidence curves for the statin category did not reach a statistical significance $(\log$-rank $\mathrm{p}=0.11)$.

\section{Multivariate analysis}

To obtain HRs for HF hospitalization of the statin groups, Cox's proportional hazard analysis was examined. Multivariate analysis showed that the effect of the statin category on $\mathrm{HF}$ hospitalization was independent of age, sex, hypertension, ln [BNP $(\mathrm{pg} / \mathrm{mL})], \mathrm{HbAlc}$, eGFR, and LDL cholesterol levels ( $\mathrm{P}$ for trend=0.002). In the model, HRs for HF in the moderate-intensity and low-intensity statin groups, in comparison to the no statin group, were 0.30 (95\% CI 0.13 to 0.63 , $\mathrm{p}=0.0008$ ) and 0.97 (0.62 to $1.52, \mathrm{p}=0.90)$, respectively, while the HR for the moderate-intensity statin group versus the low-intensity statin group was $0.31 \quad(0.13$ to 0.65 , $\mathrm{p}=0.0014$ ) (table 2).
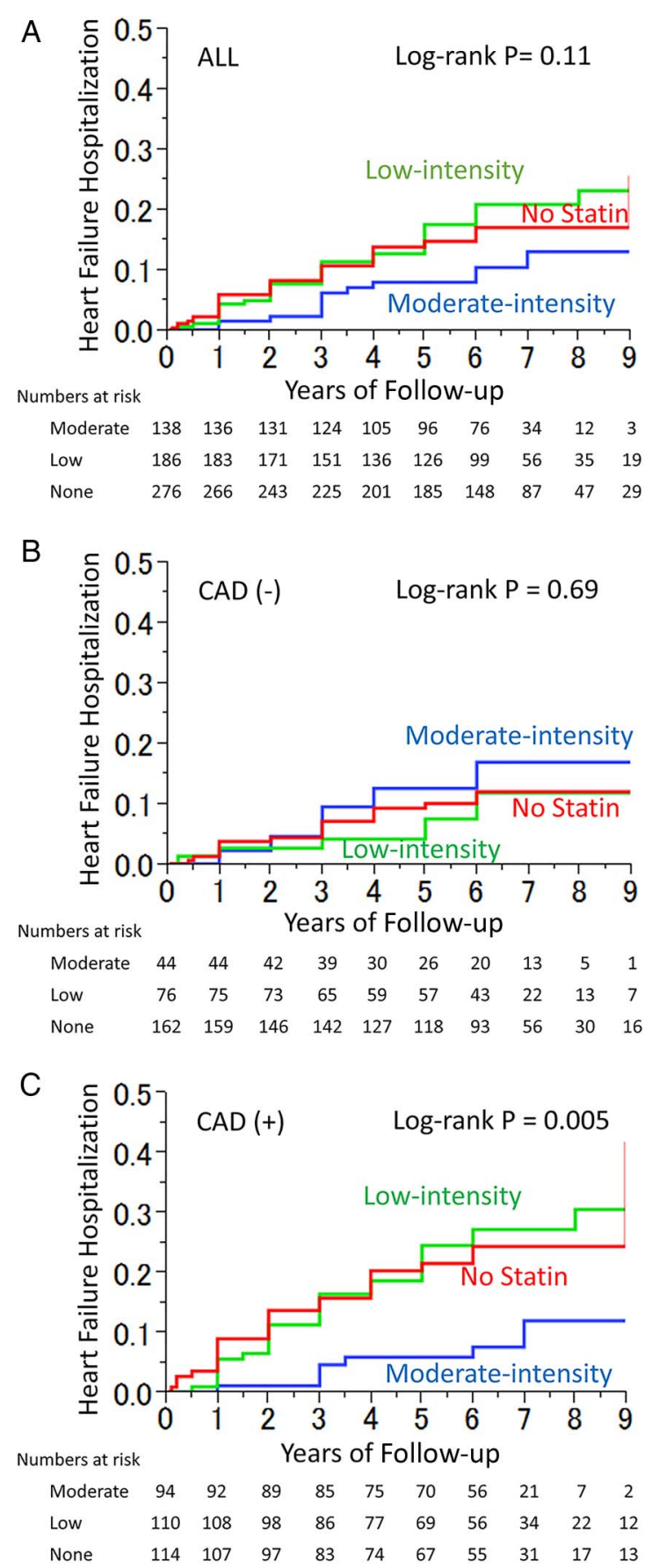

Figure 1 Kaplan-Meier estimates of the incidence of first heart failure hospitalization during follow-up according to the statin category among patients with type 2 diabetes in all $(A)$ or stratified by the absence $(B)$ or the presence $(C)$ of coronary artery disease (CAD) (blue lines, moderate-intensity statin group; green lines, low-intensity statin group; red lines, no statin group).

\section{Effects of statin category on HF hospitalization in patients with or without prevalent CAD}

Cox's proportional hazard analysis was performed next with stratification by the presence or absence of prevalent CAD.

In the patients without prevalent $\mathrm{CAD}$ at the baseline, no significant difference was demonstrated among the 
Table 2 Adjusted HR of the statin category for new heart failure hospitalization according to the CAD and LDL categories

\begin{tabular}{|c|c|c|c|c|c|c|c|c|c|}
\hline CAD category & LDL category & Statin category & Referent & HR & Lower $\mathrm{Cl}$ & Upper CI & p Value & $\begin{array}{l}\text { Number } \\
\text { of patients }\end{array}$ & $\begin{array}{l}\text { Number } \\
\text { of events }\end{array}$ \\
\hline \multirow[t]{9}{*}{ ALL } & \multirow[t]{3}{*}{ ALL } & Low & None & 0.97 & 0.62 & 1.52 & 0.90 & \multirow[t]{3}{*}{534} & \multirow[t]{3}{*}{94} \\
\hline & & Moderate & None & 0.30 & 0.13 & 0.63 & 0.0008 & & \\
\hline & & Moderate & Low & 0.31 & 0.13 & 0.65 & 0.0014 & & \\
\hline & \multirow[t]{3}{*}{$<100 \mathrm{mg} / \mathrm{dL}$} & Low & None & 1.23 & 0.52 & 2.97 & 0.63 & \multirow[t]{3}{*}{194} & \multirow[t]{3}{*}{29} \\
\hline & & Moderate & None & 0.25 & 0.05 & 0.85 & 0.025 & & \\
\hline & & Moderate & Low & 0.20 & 0.04 & 0.66 & 0.007 & & \\
\hline & \multirow[t]{3}{*}{$\geq 100 \mathrm{mg} / \mathrm{dL}$} & Low & None & 0.88 & 0.50 & 1.52 & 0.66 & \multirow[t]{3}{*}{340} & \multirow[t]{3}{*}{65} \\
\hline & & Moderate & None & 0.40 & 0.13 & 0.97 & 0.042 & & \\
\hline & & Moderate & Low & 0.45 & 0.15 & 1.13 & 0.09 & & \\
\hline \multirow[t]{9}{*}{ CAD (-) } & \multirow[t]{3}{*}{ ALL } & Low & None & 1.09 & 0.41 & 2.59 & 0.86 & \multirow[t]{3}{*}{249} & \multirow[t]{3}{*}{32} \\
\hline & & Moderate & None & 0.38 & 0.05 & 1.54 & 0.19 & & \\
\hline & & Moderate & Low & 0.35 & 0.05 & 1.70 & 0.20 & & \\
\hline & \multirow[t]{3}{*}{$<100 \mathrm{mg} / \mathrm{dL}$} & Low & None & 5.81 & 0.49 & 130 & 0.16 & \multirow[t]{3}{*}{83} & \multirow[t]{3}{*}{10} \\
\hline & & Moderate & None & 0.47 & 0.02 & 7.47 & 0.60 & & \\
\hline & & Moderate & Low & 0.08 & 0.00 & 3.03 & 0.18 & & \\
\hline & \multirow{3}{*}{$\geq 100 \mathrm{mg} / \mathrm{dL}$} & Low & None & 0.91 & 0.28 & 2.53 & 0.87 & \multirow[t]{3}{*}{166} & \multirow[t]{3}{*}{22} \\
\hline & & Moderate & None & 0.41 & 0.02 & 2.63 & 0.39 & & \\
\hline & & Moderate & Low & 0.45 & 0.02 & 3.55 & 0.48 & & \\
\hline \multirow[t]{9}{*}{ CAD (+) } & \multirow[t]{3}{*}{ ALL } & Low & None & 0.86 & 0.49 & 1.50 & 0.59 & \multirow[t]{3}{*}{285} & \multirow[t]{3}{*}{62} \\
\hline & & Moderate & None & 0.24 & 0.09 & 0.55 & 0.0006 & & \\
\hline & & Moderate & Low & 0.27 & 0.10 & 0.63 & 0.0015 & & \\
\hline & \multirow[t]{3}{*}{$<100 \mathrm{mg} / \mathrm{dL}$} & Low & None & 0.87 & 0.28 & 2.79 & 0.81 & \multirow[t]{3}{*}{111} & \multirow[t]{3}{*}{19} \\
\hline & & Moderate & None & 0.13 & 0.02 & 0.68 & 0.014 & & \\
\hline & & Moderate & Low & 0.15 & 0.02 & 0.64 & 0.008 & & \\
\hline & \multirow[t]{3}{*}{$\geq 100 \mathrm{mg} / \mathrm{dL}$} & Low & None & 0.80 & 0.39 & 1.59 & 0.52 & \multirow[t]{3}{*}{174} & \multirow[t]{3}{*}{43} \\
\hline & & Moderate & None & 0.30 & 0.08 & 0.87 & 0.026 & & \\
\hline & & Moderate & Low & 0.38 & 0.11 & 1.07 & 0.07 & & \\
\hline
\end{tabular}

HRs were adjusted by age, sex, hypertension, In [BNP (pg/mL)], HbA1c, eGFR and LDL cholesterol levels.

BNP, B-type natriuretic peptide; CAD, coronary artery disease; eGFR, estimated glomerular filtration rate; HbA1c, glycated hemoglobin;

LDL, low-density lipoprotein.

statin categories (log-rank $\mathrm{p}=0.96)$ (figure 1B). Multivariate analysis showed that $\mathrm{HF}$ hospitalization during follow-up was significantly associated with $\ln$ [BNP $(\mathrm{pg} / \mathrm{mL})]$ ( $\mathrm{P}$ for trend=0.0001) and eGFR ( $\mathrm{P}$ for trend $=0.0001$ ) but not with the statin category ( $\mathrm{P}$ for trend=0.39). HRs for the moderate-intensity and lowintensity statin groups with the no statin group as a reference were 0.38 (95\% CI 0.05 to $1.54, \mathrm{p}=0.19)$ and 1.09 ( 0.41 to $2.59, \mathrm{p}=0.86)$, respectively, while the ratio for the moderate-intensity statin group compared with the low-intensity statin group was 0.35 (0.05 to $1.70, \mathrm{p}=0.20)$ (table 2).

In contrast, in the patients with prevalent CAD at the baseline, there was a significant difference among the statin groups $(\log -r a n k p=0.003$ ) (figure $1 \mathrm{C}$ ). Cox regression analysis revealed that the effect of the statin category on $\mathrm{HF}$ hospitalization was significant ( $\mathrm{P}$ for trend $=0.0014)$ and independent of age, sex, hypertension, ln [BNP (pg/mL)], HbA1c, eGFR, and LDL at baseline. Adjusted HRs for the moderate-intensity and low-intensity statin groups compared with the no statin group as a reference were 0.24 (95\% CI 0.09 to 0.55 , $\mathrm{p}=0.0006)$ and $0.86(0.49$ to $1.50, \mathrm{p}=0.59)$, respectively, while the ratio for the moderate-intensity statin group compared with the low-intensity statin group was 0.27 (0.10 to $0.63, \mathrm{p}=0.0015)$ (table 2$)$.

\section{Effect of the statin category on HF hospitalization stratified by the baseline LDL category}

We next determined the effects of statin administration according to the baseline LDL category with a cut point of $100 \mathrm{mg} / \mathrm{dL}$. In patients without prevalent CAD, the rates of $\mathrm{HF}$ hospitalization were not significantly different among the statin categories irrespective of the LDL category (table 2). On the other hand, in patients with prevalent CAD, adjusted HRs for the moderate-intensity and low-intensity statin groups compared with the no statin group were $0.13(95 \%$ CI 0.02 to $0.68, \mathrm{p}=0.014)$ and 0.87 ( 0.28 to $2.79, \mathrm{p}=0.81)$, respectively, for patients with their LDL levels $<100 \mathrm{mg} / \mathrm{dL}$, and were $0.30(0.08$ to $0.87, \mathrm{p}=0.026)$ and $0.80(0.39$ to $1.59, \mathrm{p}=0.52)$, respectively, for patients with $\mathrm{LDL}$ levels $\geq 100 \mathrm{mg} / \mathrm{dL}$ (table 2). Interestingly, among patients with prevalent CAD and with their LDL levels controlled to less than $100 \mathrm{mg} / \mathrm{dL}$, the moderate-intensity statin group had a significantly lower HF hospitalization rate compared with the low-intensity statin group with an adjusted HR of 0.15 (0.02 to $0.64, \mathrm{p}=0.008)$. 


\section{Effects of the statin category on CAD events during}

follow-up

Since a CAD event could lead to subsequent HF hospitalization, we also examined if the statin category was associated with CAD events during follow-up. Either in all patients or in patients with prevalent CAD, the statin category was not associated with incident CAD events during follow-up (see online supplementary figure S1). When only ACS events were examined in patients with prevalent CAD (see online supplementary figure S2), there was a tendency for the moderate-intensity statin group to have fewer ACS events than the no statin group, but the difference was not statistically significant. Adjusted HRs of the moderate-intensity and low-intensity statin groups compared with the no statin group were 0.46 (95\% CI 0.17 to $1.12, \mathrm{p}=0.09)$ and 0.70 (0.33 to $1.43, \mathrm{p}=0.33)$, respectively.

\section{Sensitivity analysis}

When analyzing only patients whose follow-up began during November 2005 to November 2007, the latter half of the entry period, the moderate-intensity statin group still had a significantly lower HF hospitalization rate compared with the low-intensity statin group or the no statin group with an HR of 0.18 (0.04 to 0.62 , $\mathrm{p}=0.0056)$ or 0.22 (0.05 to $0.71, \mathrm{p}=0.001)$, respectively.

We also divided the patients by their baseline plasma BNP level with a cut point of $100 \mathrm{pg} / \mathrm{mL}$ and evaluated the effects of the statin category on HF events. In patients with $\mathrm{BNP} \geq 100 \mathrm{pg} / \mathrm{mL}$, the HRs of the moderate-intensity statin group were 0.50 (0.19 to 1.22 , $\mathrm{p}=0.13$ ) compared with the no statin group and 0.47 (0.17 to $1.19, \mathrm{p}=0.11)$ compared with the low-intensity statin group. In patients with $\mathrm{BNP}<100 \mathrm{pg} / \mathrm{mL}, \mathrm{HRs}$ of the moderate-intensity statin group were 0.09 (0.01 to $0.43, \mathrm{p}=0.0007)$ compared with the no statin group and 0.1 (0.01 to $0.49, \mathrm{p}=80.002)$ compared with the lowintensity statin group. In the analysis including the diastolic dimension of the left ventricle in the adjustment factors instead of BNP, the statin category was still significantly associated with future HF hospitalization during follow-up ( $\mathrm{P}$ for trend=0.011). Adjusted HRs for the moderate-intensity statin group were 0.36 ( 0.15 to 0.74 , $\mathrm{p}=0.004$ ) compared with the no statin group and 0.37 (0.16 to $0.77, \mathrm{p}=0.007)$ compared with the low-intensity statin group.

When patients who developed CAD prior to HF were censored at the time of the CAD event, there was a significant association between the statin category and $\mathrm{HF}$ not in patients without prevalent $\mathrm{CAD}(\mathrm{P}$ for trend $=0.24$ ) but in patients with prevalent CAD ( $\mathrm{P}$ for trend=0.015). Adjusted HRs for the moderate-statin group compared with the no statin group and to the low-intensity statin group were 0.21 (95\% CI 0.01 to $1.22, \mathrm{p}=0.089)$ and 0.24 ( 0.01 to $1.73, \mathrm{p}=0.17)$, respectively, for patients without prevalent $\mathrm{CAD}$, and were 0.33 (0.12 to $0.73, \mathrm{p}=0.006)$ and 0.37 ( 0.14 to $0.82, \mathrm{p}=0.014)$, respectively, for patients with prevalent CAD.

\section{DISCUSSION}

In patients with type 2 diabetes, we examined the effect of baseline statin category on future HF hospitalization and found a significantly decreased rate of HF hospitalization in the moderate-intensity statin group compared with the low-intensity or no statin group. The association between the statin category and HF development persisted after adjusting for possible confounding factors.

Since HF incidence rates are 2-5 times greater in patients with diabetes than those in the general population, ${ }^{13}$ it is important to establish the proper management of patients with diabetes for HF prevention. ${ }^{14}$ While several papers reported the effect of glucose control in $\mathrm{HF}$ incidence among patients with diabetes, ${ }^{11}{ }^{15-17}$ the role of statins and their intensity in HF prevention were poorly studied and understood. Guidelines recommend that, in addition to lifestyle therapy, at least moderate-intensity statin treatment should be considered if clinically indicated in patients with diabetes, ${ }^{45}$ since trials including patients with diabetes showed that statin therapy leads to significant reductions in all-cause and cardiovascular mortalities. ${ }^{8}$ However, while the clinical trials on which the guidelines are based were aiming primarily for composite end points, it is not certain whether and which statins prevent $\mathrm{HF}$ per se in patients with diabetes. Although observational, this study offers an important clue which suggests that therapy with moderate-intensity statins could prevent HF morbidity in patients with diabetes.

In this study, the effect of the statin category was apparent, especially in patients with prevalent CAD but without overt $\mathrm{HF}(\mathrm{BNP}<100 \mathrm{pg} / \mathrm{mL})$. While there was a tendency toward the beneficial effect of moderate-intensity statins, the difference among the statin categories did not reach statistical significance in patients with progressed HF (BNP level $\geq 100 \mathrm{pg} / \mathrm{mL}$ ). Although it is recommended that, in all patients with a history of CAD, statins should be used to prevent symptomatic $\mathrm{HF}$ and cardiovascular events, ${ }^{18}$ recent clinical trials prospectively investigating the use of rosuvastatin in patients with chronic HF did not demonstrate a beneficial effect on secondary prevention for HF. ${ }^{19}{ }^{20}$ In contrast, in a cohort of patients with CAD without prevalent $\mathrm{HF}$, the effect of simvastatin $20-40 \mathrm{mg}$ was shown to prevent future HF incidence. ${ }^{21}$ Therefore, the benefit of statins might depend on the baseline levels of HF severity and could become more prominent when used in patients at a certain point (ie, CAD without $\mathrm{HF}$ ) in the cardiovascular disease continuum.

Interestingly, in this study, the effect of the statin category was independent of baseline LDL levels, and, even in patients whose LDL levels were controlled to less than $100 \mathrm{mg} / \mathrm{dL}$, the moderate-intensity statin group had significantly lower HF incidence than the low-intensity or no statin groups. Since pleiotropic effects of statins are thought to be beneficial for HF prevention, ${ }^{10}$ these results appeared to be consistent with the effect of statin outside lipid lowering and with the 2015 management 
guideline of the American Diabetes Association, ${ }^{5}$ which was revised to recommend when to initiate which statin based on the risk profile rather than LDL levels.

The association between the statin category and HF incidence could be confounded by a CAD event during follow-up since coronary events such as MI often lead to cardiac dysfunction and subsequent HF. Therefore, we examined if the statin category affects the rate of cardiovascular events or ACS and found no significant difference among the statin groups. Furthermore, the effect of the statin category on HF was consistent in the analysis where patients who had CAD events prior to $\mathrm{HF}$ events were censored at the time of the CAD event (ie, the incident HF occurred only in those who had no clinical CAD event during follow-up). These results suggest that the effect of the statin category on HF hospitalization was independent of CAD events.

In this study, HF incidence was significantly lower in patients with diabetes taking moderate-intensity statins at baseline. Since moderate-intensity statins were available and became popular in later years than low-intensity statins, it was possible that the observed difference among statins could simply reflect the improved prevention of HF in modern medicine. To exclude this possibility, the effects of the statin category were next examined only in patients enrolled during November 2005 to November 2007, the latter half of the entry period, which revealed that the moderate-intensity statin group still had a significantly lower HF hospitalization rate compared with the low-intensity and no statin groups.

Limitations in this study include the following: since the study was performed in a cardiovascular center, the generalizability needs to be confirmed. In addition, in this study, only $6.9 \%$ of the patients had their baseline LDL levels below $70 \mathrm{mg} / \mathrm{dL}$. Therefore, we could not perform the analysis using an LDL cut-off of $70 \mathrm{mg} / \mathrm{dL}$. Furthermore, although planned carefully, the observational nature of the study could contain several biases. Since some baseline variables including age of subjects were significantly different in the statin category (table 1), even using the statistics to minimize and quantify these effects, a selection bias could still affect the results. For example, the choice of the statin intensity could be related to a clinical decision based on the patient profiles. In fact, in patients without $\mathrm{CAD}$ and with $\mathrm{LDL}<100 \mathrm{pg} / \mathrm{mL}$, the low-intensity statin group had an insignificant but higher risk for HF than the no statin group with an adjusted HR of 5.8, while in patients of other groups the ratios were $0.8-0.9$ (table 2). It is most likely that the absence of difference in the HF risk between the low-intensity and no intensity groups was attributed largely to the baseline difference in patient population, thus leading to the absence of the overall dose-related effect of the statin category in prevention of HF.

In summary, patients with type 2 diabetes taking moderate-intensity statins had lower HF hospitalization incidence than those taking low-intensity statins or not taking any statin. The effect of the statin intensity was irrespective of LDL levels and apparent, especially in diabetes with prevalent $\mathrm{CAD}$ or with $\mathrm{BNP}<100 \mathrm{pg} / \mathrm{mL}$. Whether administration of higher intensity statins to these patients could lead to lower HF risks should be confirmed with further studies.

Acknowledgements The authors thank all the investigators and all the patients who took part in the study. They also thank Mrs Nahoko Mochizuki and Mrs Chikako Tokudome of the National Cerebral and Cardiovascular Center for their excellent secretarial assistance.

Contributors IK designed the study, analyzed the data and wrote the manuscript. HM, YO, TT, and MT contributed to the collection, assembly, analysis and interpretation of data. TA contributed to the discussion and reviewed/edited the manuscript as a heart failure specialist. KK contributed to the discussion and reviewed/edited the manuscript as an expert on cardiology. TN and SY contributed to the discussion and reviewed/edited the manuscript as experts on coronary artery diseases. $\mathrm{HO}$ supervised the whole work. All authors meet all four criteria for authorship in ICMJE

Recommendations 2013 and have the opportunity to participate in the review, drafting, and final approval of the manuscript. IK takes responsibility for the work as a whole, including the study design, access to data, and the decision to submit and publish the manuscript.

Funding This work was partly supported by the Research Grants for Cardiovascular Diseases from the Ministry of Health, Labor and Welfare and from the Ministry of Education, Culture, Sports, Science and Technology and by the Intramural Research Fund (26-4-6) for Cardiovascular Diseases of the National Cerebral and Cardiovascular Center.

\section{Competing interests None declared.}

Ethics approval This observational study followed the World Medical Association's Declaration of Helsinki and was approved by the Institutional Review Board of National Cerebral and Cardiovascular Center.

Provenance and peer review Not commissioned; externally peer reviewed.

\section{Data sharing statement No additional data are available.}

Open Access This is an Open Access article distributed in accordance with the Creative Commons Attribution Non Commercial (CC BY-NC 4.0) license, which permits others to distribute, remix, adapt, build upon this work noncommercially, and license their derivative works on different terms, provided the original work is properly cited and the use is non-commercial. See: http:// creativecommons.org/licenses/by-nc/4.0/

\section{REFERENCES}

1. Cannon $\mathrm{CP}$, Braunwald $\mathrm{E}, \mathrm{McCabe} \mathrm{CH}$, et al, Pravastatin or Atorvastatin Evaluation and Infection Therapy-Thrombolysis in Myocardial Infarction 22 Investigators. Intensive versus moderate lipid lowering with statins after acute coronary syndromes. $N$ Engl J Med 2004;350:1495-504.

2. de Lemos JA, Blazing MA, Wiviott SD, et al, Investigators. Early intensive vs a delayed conservative simvastatin strategy in patients with acute coronary syndromes: phase $\mathrm{Z}$ of the $\mathrm{A}$ to $\mathrm{Z}$ trial. JAMA 2004;292:1307-16.

3. Nissen SE, Tuzcu EM, Schoenhagen P, et al, REVERSAL Investigators. Effect of intensive compared with moderate lipid-lowering therapy on progression of coronary atherosclerosis: a randomized controlled trial. JAMA 2004;291:1071-80.

4. Stone NJ, Robinson JG, Lichtenstein AH, et al, American College of Cardiology/American Heart Association Task Force on Practice Guidelines. 2013 ACC/AHA guideline on the treatment of blood cholesterol to reduce atherosclerotic cardiovascular risk in adults: a report of the American College of Cardiology/American Heart Association Task Force on Practice Guidelines. J Am Coll Cardiol 2014;63:2889-934.

5. American Diabetes Association. Standards of medical care in diabetes-2015. Diab Care 2015;38:S1-94.

6. Colhoun HM, Betteridge DJ, Durrington PN, et al, CARDS Investigators. Primary prevention of cardiovascular disease with atorvastatin in type 2 diabetes in the Collaborative Atorvastatin Diabetes Study (CARDS): multicentre randomised placebo-controlled trial. Lancet 2004;364:685-96. 
7. Taylor F, Huffman MD, Macedo AF, et al. Statins for the primary prevention of cardiovascular disease. Cochrane Database Syst Rev 2013;(1):CD004816.

8. Kearney PM, Blackwell L, Collins R, et al., Cholesterol Treatment Trialists' (CTT) Collaborators. Efficacy of cholesterol-lowering therapy in 18,686 people with diabetes in 14 randomised trials of statins: a meta-analysis. Lancet 2008;371:117-25.

9. Davignon J. Beneficial cardiovascular pleiotropic effects of statins. Circulation 2004;109:III39-43.

10. Ramasubbu K, Estep J, White DL, et al. Experimental and clinical basis for the use of statins in patients with ischemic and nonischemic cardiomyopathy. J Am Coll Cardiol 2008;51:415-26.

11. Kishimoto I, Makino H, Ohata Y, et al. Hemoglobin A1c predicts heart failure hospitalization independent of baseline cardiac function or B-type natriuretic peptide level. Diab Res Clin Pract 2014;104:257-65.

12. Epshteyn V, Morrison K, Krishnaswamy P, et al. Utility of B-type natriuretic peptide (BNP) as a screen for left ventricular dysfunction in patients with diabetes. Diabetes Care 2003;26:2081-7.

13. Nichols GA, Gullion CM, Koro CE, et al. The incidence of congestive heart failure in type 2 diabetes: an update. Diabetes Care 2004;27:1879-84.

14. Bell DS. Heart failure: the frequent, forgotten, and often fatal complication of diabetes. Diabetes Care 2003;26:2433-41.

15. Iribarren C, Karter AJ, Go AS, et al. Glycemic control and heart failure among adult patients with diabetes. Circulation 2001;103:2668-73.
16. Stratton IM, Adler Al, Neil HA, et al. Association of glycaemia with macrovascular and microvascular complications of type 2 diabetes (UKPDS 35): prospective observational study. BMJ 2000;321:405-12.

17. Pazin-Filho A, Kottgen A, Bertoni AG, et al. $\mathrm{HbA} 1 \mathrm{c}$ as a risk factor for heart failure in persons with diabetes: the Atherosclerosis Risk in Communities (ARIC) study. Diabetologia 2008;51: 2197-204.

18. Yancy CW, Jessup M, Bozkurt B, et al, American College of Cardiology Foundation/American Heart Association Task Force on Practice Guidelines. 2013 ACCF/AHA guideline for the management of heart failure: a report of the American College of Cardiology Foundation/American Heart Association Task Force on practice guidelines. Circulation 2013;128:e240-327.

19. Kjekshus J, Apetrei E, Barrios V, et al, CORONA Group. Rosuvastatin in older patients with systolic heart failure. $N$ Engl $J$ Med 2007;357:2248-61.

20. Tavazzi L, Maggioni AP, Marchioli R, et al, Gissi-HF Investigators. Effect of rosuvastatin in patients with chronic heart failure (the GISSI-HF trial): a randomised, double-blind, placebo-controlled trial. Lancet 2008:372:1231-9.

21. Kjekshus J, Pedersen TR, Olsson AG, et al. The effects of simvastatin on the incidence of heart failure in patients with coronary heart disease. J Card Fail 1997;3:249-54. 